\title{
Dióxido de carbono aplicado via água de irrigação na cultura da alface.
}

\author{
Raquel A. Furlan'; Dálcio R. B. Alves'; Marcos V. Folegatti²; Tarlei A. Botrel²; Keigo Minami ${ }^{3}$ \\ ${ }^{1}$ USP-ESALQ , Doutorandos em Irrigação e Drenagem, Av. Pádua Dias, 11, 13.418-900 Piracicaba, SP. E-mail: \\ mvfolega@ carpa.ciagri.usp.br; ${ }^{2}$ USP-ESALQ, Profs. Drs. Departamento de Engenharia Rural; ${ }^{3}$ USP-ESALQ, Prof. Dr. Departamento de \\ Horticultura.
}

\section{RESUMO}

O experimento foi realizado em Piracicaba (SP), com o objetivo de avaliar os efeitos da aplicação de dióxido de carbono via água de irrigação na produtividade e qualidade de alface cultivada em ambiente protegido. Os tratamentos foram constituídos de dois ambientes protegidos, sendo um com aplicação de $\mathrm{CO}_{2}$ e o outro sem aplicação de $\mathrm{CO}_{2}$, onde se cultivou a alface cultivar Verônica. Cada um dos ambientes foi composto por oito parcelas com dimensões de $1,2 \mathrm{~m} \mathrm{x}$ $6,0 \mathrm{~m}$ e espaçadas de $0,80 \mathrm{~m}$. A cultura foi irrigada com o tubo gotejador "Rain Tape" com vazão de 1,15 L/h, pressão de serviço de $60 \mathrm{kPa}$ e espaçamento entre gotejadores de $0,20 \mathrm{~m}$. As irrigações foram feitas diariamente, tendo em vista o objetivo de aplicação diária da dose de $\mathrm{CO}_{2}$ de $50 \mathrm{~L} / \mathrm{m}^{2} / \mathrm{dia}$. As mudas de alface para o plantio foram formadas em ambiente protegido, em bandejas de isopor, contendo vermiculita como substrato. $\mathrm{O}$ transplante foi feito aos 30 dias após o semeio em canteiros de $1,2 \mathrm{~m}$ de largura por $6,0 \mathrm{~m}$ de comprimento, com espaçamento entre as plantas de $0,30 \mathrm{~m}$ e entre linhas de $0,30 \mathrm{~m}$. A aplicação de $\mathrm{CO}$ foi iniciada no dia 02 de outubro de 1997, sendo feita diariamente, estendendo-se por um período de 30 dias, quando foi então realizada a colheita final da cultura de alface. A aplicação de $\mathrm{CO}_{2}$ via água de irrigação proporcionou aumentos de área foliar e consequentemente do peso da matéria seca da parte aérea, de cerca de $27 \%$, aos 30 dias após o transplantio. O diâmetro da cabeça de alface, número de folhas e o rendimento de cabeças aumentaram em media $15,9 \%, 5,5 \%$ e $28,8 \%$, respectivamente, em comparação aos dados obtidos no tratamento sem aplicação de $\mathrm{CO}_{2}$.

Palavras-chave: Lactuca sativa L., ambiente protegido, $\mathrm{CO}_{2}$, gotejamento.

\section{ABSTRACT}

\section{Carbon dioxide water for lettuce irrigation.}

The experiment was carried out in Piracicaba, Brazil, in order to evaluate the effects of carbon dioxide, applied with the irrigation water, on the productivity and quality of the lettuce cultivated in plastic greenhouse. The treatments were designed in two plastic greenhouses, one was enriched with $\mathrm{CO}_{2}$ and the other without $\mathrm{CO}_{2}$, where lettuce variety Verônica was cultivated. The plastic greenhouse had eight plots with $1.2 \times 6.0 \mathrm{~m}$ and spaced by $0.8 \mathrm{~m}$. The crop was irrigated with "Rain Tape" drip with outflow of $1.15 \mathrm{~L} / \mathrm{h}$ at operating pressure of $60 \mathrm{kPa}$. The irrigation was scheduled on a daily basis in order to apply 50 liters $/ \mathrm{m}^{2} /$ day of $\mathrm{CO}_{2}$ daily. The seedlings were produced in plastic greenhouse by using isopor tray with vermiculite as substratum. They were transplanted 30 days after sowing date in beds of $1.2 \mathrm{~m}$ width and $6.0 \mathrm{~m}$ length, with $0.30 \mathrm{~m}$ spaced between plants and $0,30 \mathrm{~m}$ between lines. After the application of $\mathrm{CO}_{2}(10 /$ 02/97 - 11/02/97) plants were harvested. Enrichment of irrigation water with $\mathrm{CO}_{2}$ increased the leaf area, dry weight of the aerial part by $27 \%$, after 30 days of transplanting. The increase in lettuce head diameter, number of leaves and yield of heads was of $15.9 \%, 5.55 \%$ and $28.8 \%$, respectively, in relation to the plot without $\mathrm{CO}_{2}$ application.

Keywords: Lactuca sativa L., plastic greenhouse, $\mathrm{CO}_{2}$, drip irrigation.

\section{(Aceito para publicação em 31 de janeiro de 2.001)}

$\mathrm{T}$ oda a evolução que originou a moderna agricultura foi fundamentada na necessidade de aumentar a produtividade, reduzir os custos de produção e melhorar a qualidade do produto. Para atingir esses objetivos, foi necessário criar condições mais favoráveis para o desenvolvimento das plantas. Assim, surgiram novas técnicas como o cultivo protegido e a aplicação de dióxido de carbono via água de irrigação.

A alface se constitui numa das hortaliças mais consumidas pelos brasileiros. É uma planta muito tolerante às doenças e pode ser produzida sem maiores problemas durante quase todo o ano. Muitos agricultores preferem cultivá-la em ambientes protegidos e usando a alface para fazer rotação com outras espécies. Outros cultivam espécies de primavera-verão durante o inverno, quando o preço no mercado é mais alto, e durante o verão cultivam alface obtendo desse modo preços mais elevados (Sganzerla, 1995).

Os primeiros trabalhos utilizando-se enriquecimento artificial com $\mathrm{CO}_{2}$ na atmosfera interna de ambiente protegido, visando aumentar a produtividade de culturas, foram realizados há mais de 100 anos no norte da Europa. Na década de 50, devido ao desenvolvimento de técnicas modernas utilizando-se isótopos radioativos foi possível acom- panhar com clareza o processo de assimilação do $\mathrm{CO}_{2}$ pelas plantas. Também nessa época foram realizados os primeiros experimentos com injeção de $\mathrm{CO}_{2}$ diretamente na água utilizada para irrigação das culturas a céu aberto, visando aumentar a sua produtividade. Entretanto, o grande desenvolvimento dessa tecnologia ocorreu na década de 60 (Galvão, 1993). Vários estudos conduzidos com enriquecimento de dióxido de carbono em ambientes controlados e em condições de campo mostraram aumento da fotossíntese, melhor desenvolvimento das plantas e maior resistência ao estresse hídrico. Estes resultados podem ser atribuídos à maior absorção de 
dióxido de carbono pelas raízes e ao conseqüente aumento na assimilação pelo metabolismo das plantas (Arteca et al., 1979; Cooker \& Schubert, 1981).

No final dos anos 80, empresas norte-americanas que comercializavam $\mathrm{CO}_{2}$ interessaram-se pelo processo e iniciaram trabalhos com injeção de $\mathrm{CO}_{2}$ na água utilizada para irrigação, em culturas a céu aberto, visando aumentar a sua produtividade, obtendo resultados promissores (Sanches, 1992). A idéia de fertilização com $\mathrm{CO}_{2}$ dissolvido na água de irrigação se deve à dificuldade de manter alta concentração do mesmo na atmosfera de ambientes protegidos em países como Colômbia, devido aos custos elevados desses ambientes herméticos (Salazar, 1991).

Para muitas espécies é difícil estabelecer concentração ótima de $\mathrm{CO}_{2}$, pela escassez de dados encontrados na literatura. Entretanto, consultando-se resultados obtidos em pesquisas, conclui-se que a concentração ótima de $\mathrm{CO}_{2}$ para o crescimento da maioria das espécies situa-se entre 600 e $900 \mathrm{mmolCO}_{2} / \mathrm{mol}$ de ar. Em alguns casos, têm sido observadas injúrias em plantas submetidas a concentrações acima de 1.000 $\mathrm{mmolCO}_{2} / \mathrm{mol}$ de ar, o que é também uma razão adicional para manter a concentração abaixo de $900 \mathrm{mmolCO} / \mathrm{mol}$ de ar. Além disso, incrementos da concentração de $\mathrm{CO}_{2}$ também implicam no aumento de perdas devido ao vazamento do gás para o ambiente externo (Mortensen, 1987). Ambientes com elevadas concentrações de $\mathrm{CO}_{2}$ induzem pequenos acréscimos na área foliar e aumentos um pouco maiores na massa (Ford \& Thorne, 1967). O CO induz mudanças na anatomia e na morfologia das plantas, resultando em alterações no peso seco de órgãos (Acock \& Pasternak, 1986).

A temperatura ótima para fotossíntese varia com o estádio de desenvolvimento das plantas, estando na faixa de 20 a $30^{\circ} \mathrm{C}$ para a maioria das espécies, sendo menor na fase de maturação (Acock et al., 1990). Variando a concentração de $\mathrm{CO}_{2}$ e a intensidade luminosa, Ghannoum et al. (1997) obtiveram variação de $71 \%$ na massa seca de plantas $\mathrm{C}_{3}$ (Panicum laxum) e $28 \%$ de $_{4}$ (Panicum antidotade). $\mathrm{O}$ au- mento da velocidade de assimilação pode atingir $80 \%$ ao ativar a enzima ribulose 1,5 bifosfato carboxilaseoxigenase (Rubisco), reduzindo a fotorrespiração, melhorando o metabolismo, o crescimento e a produção.

$\mathrm{O}$ aumento da concentração de $\mathrm{CO}_{2}$ induz o fechamento parcial dos estômatos, causando, como conseqüência, redução na transpiração (Faquhar et al., 1978; Kimball, 1983; Kimball \& Idso, 1983; Morison, 1985; Cure \& Acock, 1986). Nesta situação há aumento da taxa de crescimento, com produção de maior quantidade de matéria vegetativa e aumento da área foliar (Morison \& Gifford, 1984).

Kimball (1983) revisou 70 publicações apresentadas nos últimos 64 anos referentes ao efeito do enriquecimento do ambiente com $\mathrm{CO}_{2}$ sobre a produtividade de várias espécies de plantas. Os resultados mostraram aumento de $33 \%$ na produtividade com a duplicação da concentração de $\mathrm{CO}_{2}$ da atmosfera.

$\mathrm{O}$ enriquecimento do ambiente de túneis plásticos cultivados com pepino, alface e pimentão, a uma concentração de $10.000 \mathrm{mmolCO} / \mathrm{mol}$ de ar por um período de uma a duas horas antes do nascer do sol, resultou em desenvolvimento mais rápido das plantas, frutos precoces e aumento da produtividade de pepino e alface em cerca de $45 \%$ em relação à testemunha. Já a cultura de pimentão teve maior número de frutos e acréscimo de $20 \%$ na produção (Enoch et al.,1970). D'Andria et al. (1990) verificaram aumento no peso do fruto de tomate de 98 para $105 \mathrm{~g}$ e na produção de 84 para 97 t/ha com uso de $\mathrm{CO}_{2}$ via água de irrigação. Entretanto, Hartz \& Holt (1991) não encontraram diferença de produtividade em tomate com fornecimento artificial de $\mathrm{CO}_{2}$. Fernandez Bayon et al. (1993) observaram maior crescimento de raízes, brotação e número de flores por planta com aplicação de $\mathrm{CO}_{2}$ via água de irrigação na cultura de melão.

A aplicação de $\mathrm{CO}_{2}$ via água de irrigação induziu aumento do conteúdo de clorofila da folha, da absorção de zinco e manganês e da produtividade de algodão (Mauney \& Hendrix, 1988). A aplicação de $1.100 \mathrm{mmolCO}_{2} / \mathrm{mol}$ de ar via água de irrigação em uva, durante 37 dias no inverno, proporcionou aumento de $36 \%$ na sua produtividade (Kurooka et al., 1990). Trabalhando com soja, Prior et al. (1991) verificaram aumento na área foliar e maior potencial no xilema ao meio dia com aplicação de $\mathrm{CO}_{2}$ via água de irrigação. Em experimentos com curtos períodos de tempo de aplicação $\mathrm{CO}_{2}$, o aumento da concentração induziu aumento da fotossíntese em até $52 \%$ e da produção de ervilha em 29\% (Mudrik et al.,1997).

Em condições de ambiente protegido, com e sem a aplicação de $\mathrm{CO}_{2}$ via água de irrigação, Pinto (1997) verificou que a maior produtividade de melão foi obtida no ambiente com aplicação de $1.170 \mathrm{mmolCO} / \mathrm{mol} \mathrm{de} \mathrm{ar} \mathrm{via}$ água de irrigação, durante um período de trinta minutos, apresentando incremento de produtividade de $27,3 \%$ em relação ao tratamento sem $\mathrm{CO}_{2}$.

No Brasil, recentemente iniciou-se a aplicação de $\mathrm{CO}_{2}$ via água de irrigação, mas há carência de trabalhos referentes ao assunto. Portanto, são necessários estudos para analisar os efeitos da aplicação de $\mathrm{CO}_{2}$ via água de irrigação para as culturas, visando aperfeiçoar o uso dessa técnica. Assim, objetivo desse trabalho foi avaliar a produção quantitativa e qualitativa de alface em decorrência da aplicação de $\mathrm{CO}_{2}$ via fertirrigação.

\section{MATERIAL E MÉTODOS}

O experimento foi realizado em ambiente protegido na área experimental da USP - ESAL em Piracicaba, SP, de 25 de setembro a 25 de outubro de 1997. As coordenadas geográficas do local são $22^{\circ} 42^{\prime}$ de latitude sul, $47^{\circ} 38^{\prime}$ de longitude oeste e altitude de $575 \mathrm{~m}$. O clima é do tipo CWA, subtropical úmido, conforme classificação de Köppen.

Utilizou-se a alface cultivar Verônica crespa, submetida a dois ambientes protegidos, sendo um com a aplicação de $\mathrm{CO}_{2}\left(50,5 \mathrm{~L} / \mathrm{m}^{2} /\right.$ dia de $\left.\mathrm{CO}_{2}\right) \mathrm{e}$ o outro sem aplicação, em delineamento inteiramente casualizado. Cada ambiente foi composto por oito parcelas com dimensões de 1,2 m x 6,0 m, espaçadas de $0,80 \mathrm{~m}$, consideradas como repetições. 
As mudas de alface foram formadas em bandejas de isopor e vermiculita como substrato em casa de vegetação e transplantadas com cerca de 30 dias, com as plântulas apresentando de três a quatro folhas. Cada parcela foi constituída de quatro linhas de plantas espaçadas de $0,3 \mathrm{~m} \times 0,3 \mathrm{~m}$. As parcelas foram cobertas com filme de polietileno preto, considerando-se como área útil a linha central de plantas.

A adubação foi feita segundo a análise química de solo baseando-se nas recomendações do Instituto Agronômico de Campinas (Raij et al., 1986). Foram utilizadas $67 \mathrm{~g} / \mathrm{m}^{2}$ de superfosfato simples e $3,3 \mathrm{~g} / \mathrm{m}^{2}$ de cloreto de potássio. Para a adubação de cobertura foram adicionadas $4,4 \mathrm{~g} / \mathrm{m}^{2}$ de uréia, divididas em quatro aplicações iguais via fertirrigação, a cada sete dias.

A irrigação foi feita com o tubo gotejador "Rain Tape" com vazão de $1,15 \mathrm{~L} / \mathrm{h}$, pressão de serviço de $60 \mathrm{kPa}$ e espaçamento entre gotejadores de 0,20 m. O manejo da irrigação baseou-se na evaporação do Tanque Classe A, repondo diariamente $100 \%$ da evaporação do tanque.

$\mathrm{O}$ sistema de aplicação de $\mathrm{CO}_{2}$ foi composto de um cilindro de dióxido de carbono de alta pressão, equipado com uma válvula dosadora para qualificar o $\mathrm{CO}_{2}$ liberado do cilindro, manômetro e um injetor venturi para introduzir $\mathrm{CO}_{2}$ na linha de irrigação. A aplicação foi iniciada no dia 02 de outubro de 1997, estendendo-se até a colheita final da cultura. A injeção na linha de irrigação foi feita a partir das 11:00 h, por um período de aproximadamente 40 minutos, durante a aplicação da lâmina de irrigação.

A cada cinco dias, a partir dos sete dias após o plantio, foram colhidas oito plantas, sendo uma em cada parcela, para avaliar o diâmetro das cabeças de alface, número de folhas, massa seca da parte aérea e área foliar, com uso do integrador de área foliar modelo LICOR LI 3100. Para a determinação do diâmetro da cabeça, foram tomadas duas medidas transversais da planta, antes da colheita e obtida a média. Após a determinação da área foliar, as plantas foram acondicionadas em sacos de papel e colocadas para secar em estufa de circula-

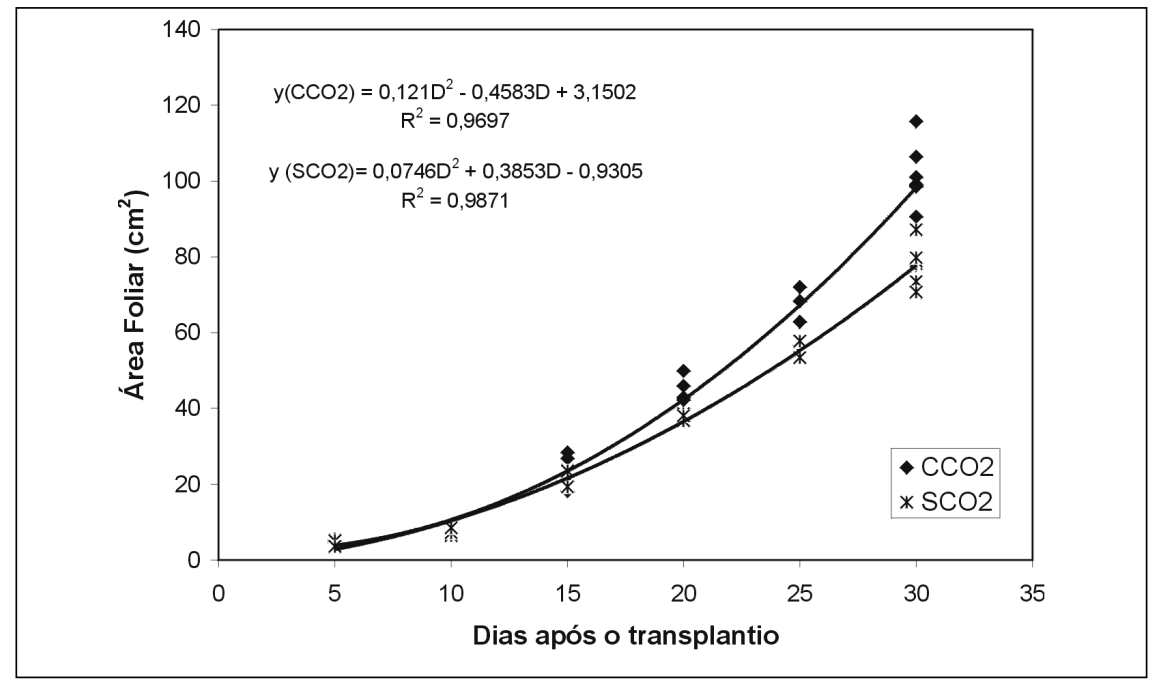

Figura 1. Área foliar de alface em função da aplicação (CCO2) ou não (SCO2) de $\mathrm{CO}_{2}$ e dos dias após o transplantio das mudas (D). Piracicaba, ESALQ, 1997.

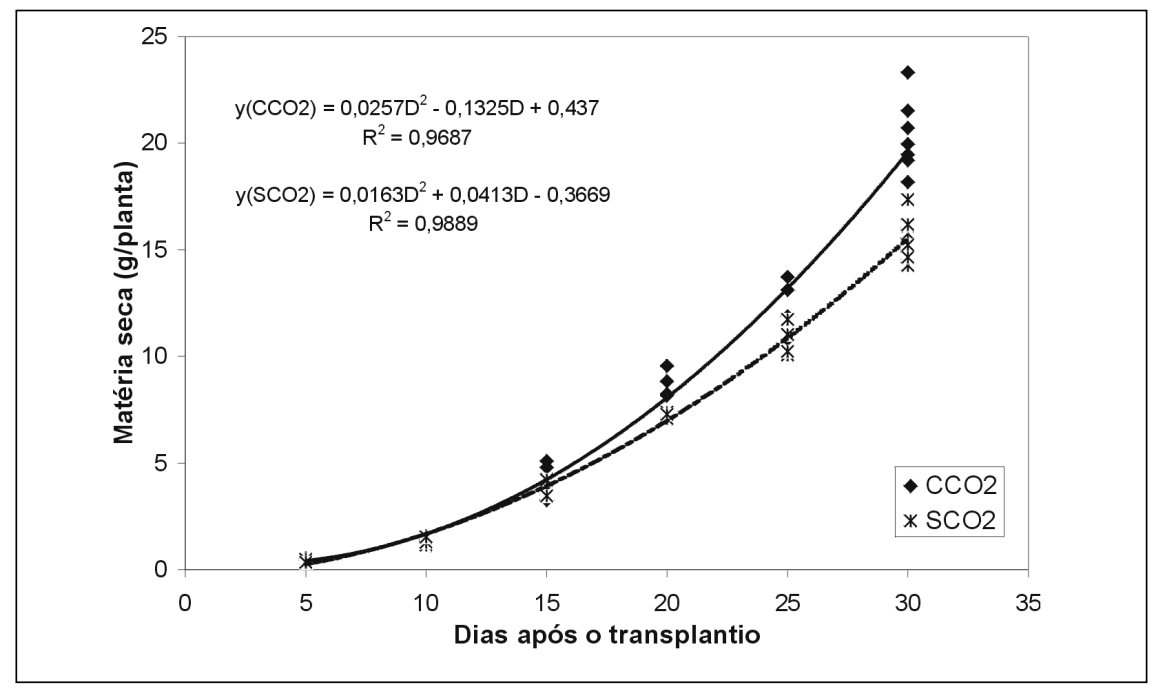

Figura 2. Matéria seca de plantas de alface em função da aplicação (CCO2) ou não (SCO2) de $\mathrm{CO}_{2}$ e dos dias após o transplantio (D). Piracicaba, ESALQ, 1997.

ção de ar forçada a $65^{\circ} \mathrm{C}$ até massa constante. Em seguida as plantas foram pesadas e determinou-se a matéria seca.

Foi aplicado o teste $\mathrm{F}$ para verificar se a aplicação de $\mathrm{CO}_{2}$ teve efeito significativo sobre as características avaliadas. A área foliar, matéria seca, diâmetro de cabeça e número de folhas foram submetidas à análise de regressão polinomial.

\section{RESULTADOS E DISCUSSÃO}

Até 15 dias após o transplantio houve certa homogeneidade entre os tratamentos quanto à área foliar (Figura 1), enquanto aos 30 dias, o valor médio de área foliar observado no ambiente com aplicação de $\mathrm{CO}_{2}$ foi de $98,55 \mathrm{~cm}^{2}$, valor esse $27,4 \%$ maior do que sem $\mathrm{CO}_{2}$, $\left(77,33 \mathrm{~cm}^{2}\right)$. Acréscimos da área foliar em beterraba açucareira, cevada, couve e milho também foram verificados por Ford \& Thorne (1967) em ambientes enriquecidos com concentrações de 1.000 a $3.000 \mathrm{mmolCO}_{2} / \mathrm{mol} \mathrm{de}$ ar.

$\mathrm{O}$ ambiente enriquecido com $\mathrm{CO}_{2}$ resultou em aumento de matéria seca das plantas de alface a partir de 15 dias após o transplantio (Figura 2), com valores médios, aos 30 dias, de 15,52 e 19,75 g/ planta, para os tratamentos sem e com a aplicação de $\mathrm{CO}_{2}$, respectivamente.

Apesar de os valores de área foliar e matéria seca terem aumentado no ambiente com a aplicação de $\mathrm{CO}_{2}$, a rela- 


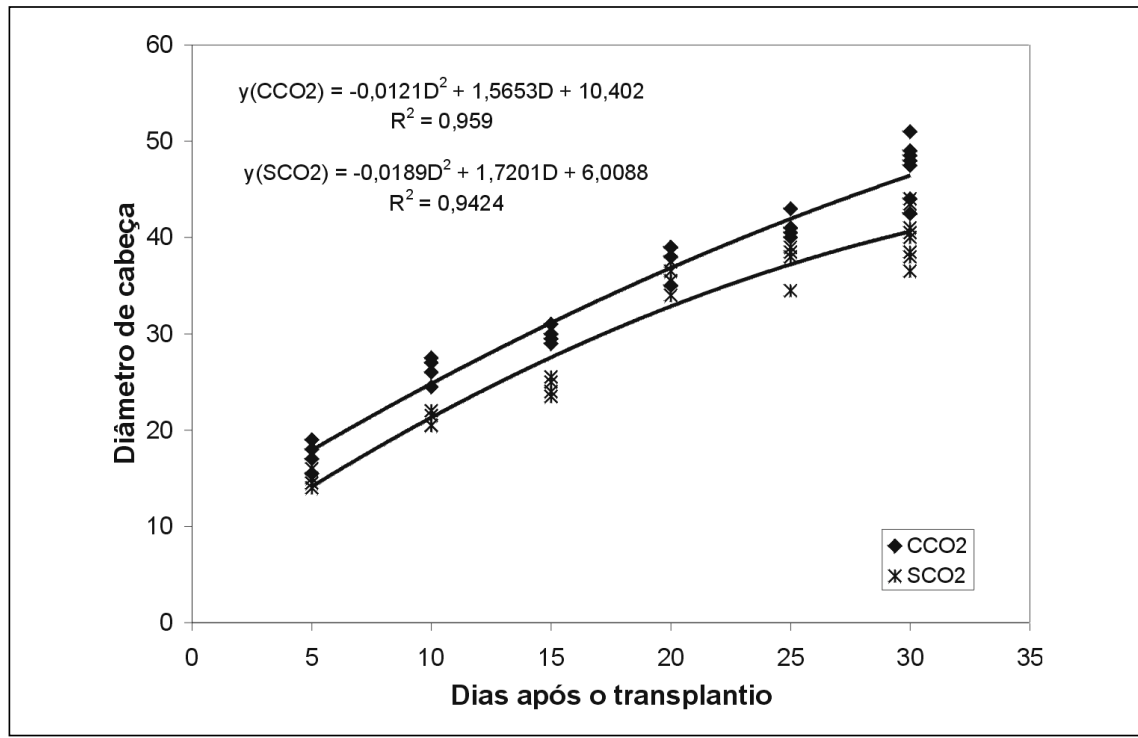

Figura 3. Diâmetro de cabeça de alface em função da aplicação (CCO2) ou não (SCO2) de $\mathrm{CO}_{2}$ e dos dias após o transplantio das mudas (D). Piracicaba, ESALQ, 1997.

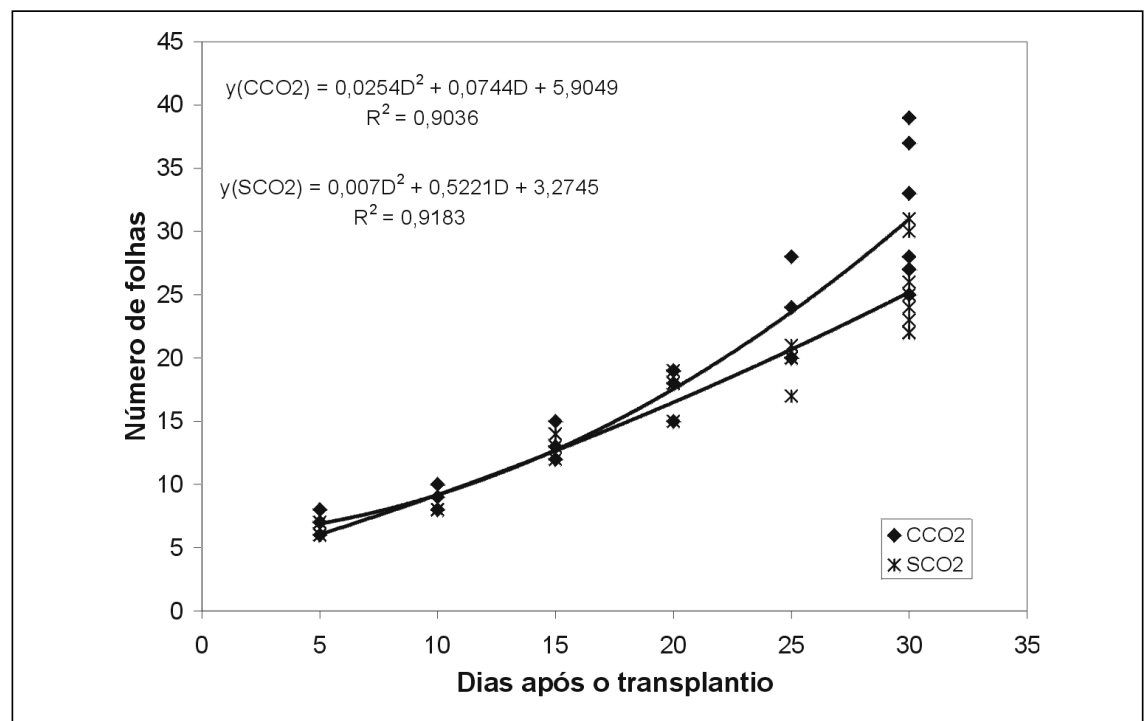

Figura 4. Número de folhas de alface em função da aplicação (CCO2) ou não (SCO2) de $\mathrm{CO}_{2}$ e dos dias após o transplantio das mudas (D). Piracicaba, ESALQ, 1997.

ção entre área foliar e matéria seca (área foliar específica) não foi alterada, apresentando valor médio de $4,9 \mathrm{~cm}^{2} / \mathrm{g}$ nos dois ambientes. Assim, o acréscimo em área foliar foi proporcional ao acréscimo em matéria seca na planta. Vários autores (Kimball \& Mitchell, 1979; D’Andria et al., 1990; Islam et al., 1996) observaram que o enriquecimento do ambiente com $\mathrm{CO}_{2}$ possibilitou produção de pepino, pimentão e tomate mais pesados, provavelmente por ter havido maior acúmulo de carboidratos nos frutos devido às altas taxas de fotossíntese encontradas nos ambientes com enriquecimento de $\mathrm{CO}_{2}$.
O valor médio do diâmetro da cabeça de alface observado no ambiente com aplicação de $\mathrm{CO}_{2}$ aos 30 dias após o transplantio foi de $46,63 \mathrm{~cm}$ e sem aplicação de $\mathrm{CO}_{2}$, de $40,25 \mathrm{~cm}$, apresentando acréscimo no diâmetro da cabeça da alface de 15,9\% (Figura 3).

O número de folhas de alface por cabeça não diferiu significativamente, nos tratamentos com ou sem aplicação de $\mathrm{CO}_{2}$, havendo, porém, tendência a apresentar aumento do número de folhas no ambiente onde houve a aplicação de $\mathrm{CO}_{2}$ (Figura 4). Aos 30 dias após o transplantio houve incremento de $5,5 \%$ no número de folhas para o trata- mento com aplicação de $\mathrm{CO}_{2}$.

$\mathrm{O}$ máximo rendimento da cultura de alface observado no ambiente com $\mathrm{CO}_{2}$ foi de 59,5 t/ha e em ambiente sem $\mathrm{CO}_{2}$ foi de 46,2 t/ha, apresentando diferença de $28,8 \%$. Enoch et al. (1970) também observaram acréscimo em massa de matéria fresca da ordem de $43 \%$ em alface cultivada em túneis de plástico sob enriquecimento de $\mathrm{CO}_{2}$ e Pinto (1997) observou aumento da produtividade com a aplicação de $\mathrm{CO}_{2}$ injetado via água de irrigação.

\section{LITERATURA CITADA}

ACOCK, B.; PASTERNAK, D. Effects of $\mathrm{CO}_{2}$ concentration on composition, anatomy and morphology of plants. In: ENOCH, H. Z.; KIMBALL, B. A. Carbon dioxide enrichment of greenhouse crops. Flórida: CRC Press, Inc, 1986. v. 2, p. 41-52.

ACOCK, B.; ACOCK, M.C.; PASTERNAK, D. Interactions of $\mathrm{CO}_{2}$ enrichment and temperature on carbohydrate production and accumulation in muskmelon leaves. Journal of the American Society for Horticultural Science, v. 115, n. 4, p. 525-529, 1990.

ARTECA, R.N.; POOVAIAH, B.W.; SMITH, O.E. Changes in carbon fixation, tuberization and growth induced by $\mathrm{CO}_{2}$ applications to the root zone of potato plants. Science, v. 205, n. 4412, p. 1279-1280, 1979.

COOKER, R.T.; SCHUBERT, K.R. Carbon dioxide fixation in soybean roots and nodules: I. Characterization and comparison with $\mathrm{N}_{2}$ fixation and comparison of xylem exudate during early nodule development. Plant Physiology, v. 67, n. 4, p. 691-696, 1981.

CURE, J.D.; ACOCK, B. Crop responses to carbon dioxide doubling: a literature survey. Agricultural Forest and Meteorology, v. 38, n. 1/3, p. 127-145, 1986.

D'ANDRIA, R.; NOVERO, R.; SHANAHAN, J.F.; MOORE, F.D. Drip irrigation of tomato using carbonated water and mulch in Colorado. Acta-Horticulturae, n. 278, p. 179-185, 1990.

ENOCH, H.Z.; RYLSKI, I.; SAMISH, Y. $\mathrm{CO}_{2}$ enrichment of cucumber, lettuce and sweet pepper plants grown in low plastic tunnels in a subtropical climate. Journal of Agriculture Research, v. 20, p. 63-69, 1970.

FAQUHAR, G.D.; DUBLE, D.R.; RASCHKE, K. Gain of the feedback loop envolving carbon dioxide and stomat, theory and measurement. Plant Physiology, v. 62, n. 3, p. 406-412, 1978.

FERNANDEZ BAYON, J.M.; BARNES, J.D.; OLLERENSHAW, J.H.; DAVISON, A.W. Physiological effects of ozone on cultivars of watermelon (Citrullus lannatus) and muskmelon (Cucumis melo) widely grown in Spain. Enviromental Pollution, v. 81, n. 3, p. 199-206, 1993.

FORD, M.A.; THORNE, G.N. Effect of $\mathrm{CO}_{2}$ concentration on growth of sugar-beet, barley, kale and maize. Annals of Botany, v. 31, n. 629, 1967. 
GALVÃO, A.C. Mecanismos de ação do $\mathrm{CO}_{2}$ nas plantas. Brasil: Líquid Carbonic, 1993, 18 p.

GHANNOUM, O.; CAEMMERER, S.V.; BARLOW, E.W.R.; CONROY, J.P. The effect of $\mathrm{CO}_{2}$ enrichment and irradiance on the growth, morphology and gas exchange of a $\mathrm{C}_{3}$ (Panicum laxum) and a $\mathrm{C}_{4}$ (Panicum antidotade) grass. Australian Journal of Plant Physiology, v. 24, n. 2, p. 227-237, 1997.

HARTZ, T.K. ; HOLT, D.B. Root-zone carbon dioxide enrichment in field does not improve tomato or cucumber yield. HortScience, v. 69, n. 11, p. $1423,1991$.

ISLAM. M.S.; MATSUI, T.; YOSHIDA, Y. Effect of carbon dioxide enrichment on physicochemical and enzymatic changes in tomato fruits at various stages of maturity. Scientia Horticulturae, v. 65, p.137-149, 1996.

KIMBALL, B.A. Carbon dioxide and agricultural yield: an assemblage and analysis of 430 prior observation. Agronomy Journal, v. 75, n. 5, p. 779-788, 1983.

KIMBALL, B.A.; IDSO, S.B. Increase atmospheric $\mathrm{CO}_{2}$ : effects on crop yield, water use, and climate. Agricultural Water Management, v. 7, n. 1, p. 55-73, 1983.

KIMBALL, B.A.; MITCHELL, S.T. Tomato yields from $\mathrm{CO}_{2}$ enrichment in unventilated and conventionally ventilated greenhouses. Journal of the American Society for Horticultural Science, v. 104, p. 515-520, 1979.
KUROOKA, H.; FUKUNAGA, S.; YUDA, E.; NAKAGAWA, S.; HORIUCHI, S.; KUROKA, H. Effect of carbon dioxide enrichment on vine growth and berry quality of "Kyoho" grapes. Journal of Horticultural Science, v. 65, n. 3, p. 463-470, 1990.

MAUNEY, J.R.; HENDRIX, D.L. Responses of glasshouse grown cotton to irrigation with carbon dioxide saturated water. Crop Science, v. 28, n. 5 , p. $835-838,1988$.

MORISON, J.I.L. Sensitivy of stomata and water use efficiency to high $\mathrm{CO}_{2}$. Plant, Cell and Environment, v. 8, p. 467-474, 1985.

MORISON, J.I.L.; GIFFORD, R.M. Plant growth and water use with limited water supply in high $\mathrm{CO}_{2}$ concentrations. I. Leaf area, water use and transpiration. Australian Journal of Plant Physiology, v. 11, n. 5, p. 361-374, 1984.

MORTENSEN, L.M. Review: $\mathrm{CO}_{2}$ enrichment in greenhouses Crop Responses Scientia Horticulturae, v. 33, p. 1-25, 1987.

MUDRIK, V.A.; ROMANOVA, A.K.; IVANOV, B.N.; NOVICHKOVA, N.S.; POLYAKOVA, V.A. Effect of increased $\mathrm{CO}_{2}$ concentration on growth, photosynthesis, and composition of Pisum sativum L. plant. Russian Journal of Plant Physiology, v. 44, n. 2, p. 165-171, 1997.

PINTO, J.M. Aplicação de dióxido de carbono via água de irrigação em meloeiro. Piracicaba: ESALQ/USP. 1997. 82 p. (Tese doutorado).
PRIOR, S.A.; ROGERS, H.H.; SIONIT, N.; PATTERSON, R.P. Effects of elevated atmospheric $\mathrm{CO}_{2}$ on water relations of soya bean. Agriculture Ecosystems and Environment, v. 35, n. 1, p. 13-25, 1991.

RAIJ, B. van; CANTARELLA, H.; QUAGGIO, J.A.; FURLANI, A.M.C. Recomendações de adubação e calagem para o Estado de São Paulo. 2.ed. Campinas: Instituto Agronômico \& Fundação IAC, 1996. 285 p. (Boletim técnico, 100)

SALAZAR, Y.S. $\mathrm{CO}_{2}$ in the fertilization by water enrichment. Chicago: Liquido Carbonico Colombiana. 1991, $29 \mathrm{p}$.

SANCHES, O.F. Efecto del enriquecimiento del microambiente con $\mathrm{CO}_{2}$ en cultivo de melon en campo abierto. México: Liquid Carbonic de Mexico. 1992, 7 p.

SGANZERLA, E. Nova agricultura: a fascinante arte de cultivar com os plásticos. 5.ed. Guaíba: Agropecuária, 1995. 341 p. 